\title{
An examination of the relationship between perceived service quality and patients' satisfaction towards healthcare services
}

\author{
Sujay M. J., ${ }^{1 *}$, Vishal J. M. ${ }^{2}$ \\ ${ }^{1}$ Research Scholar, Dept. of Studies and Research in Business Administration, Tumkur University, Tumkur, Karnataka, ${ }^{2}$ Student, \\ Faculty of Management, DHSMS, JSS Academy of Higher Education and Research, Mysuru, Karnataka, India \\ *Corresponding Author: \\ Email: sujay15@gmail.com
}

\begin{abstract}
This study attempted to measure the influence of various hospital service quality on patient's satisfaction. This study identified five dimensions of hospital service quality. These are: Clinical Care, Admission Procedure, Reliability, Trust, and Infrastructure. This study was conducted in Bellary city in Karnataka. This study employed the questionnaire method to collect data from the patients.

The examination findings have huge implications for hospital administrators. This study can also be used as a tool by the hospital administrator to recognise various dimensions of hospital service quality where improvements are needed to enhance patient's satisfaction.
\end{abstract}

Keywords: Clinical care, Trust, Reliability, Infrastructure, Service quality.

\section{Introduction}

Research in both the manufacturing and service industries exhibits that conveying high service quality generates quantifiable advantages in benefit, cost savings and market share (Zeithaml, Berry and Parasuraman, 1988). In India, the past couple of years have seen an expanding concern in regards to the healthcare services quality.

The globalization and liberalization policies fundamentally changed the health circumstance in India. With expanding awareness, the patients, as buyers expect quality in healthcare services. Quality has been appeared to be a basic part in the buyers' selection of hospital (Lynch and Schuler, 1990). In the light of these progress, there is a rising need to improve the nature of healthcare services quality.

\section{Review of Literature \\ Service quality and hospital service quality}

Parasuraman et al. (1988) defined service quality as the gap between customers' expectations of service and their perception of the service experience. They proposed SERVQUAL framework to assess perceived service quality for variety of sectors. The SERVQUAL framework has been applied to number of sectors like retail store (Dabholkar et al., 1996); hotel (Ingram and Daskalais, 1999); and hospital (Bigne et al., 2003) for assessing perceived service quality. As patients are often unable to assess the technical quality of medical services accurately and as these services are dominant in credence qualities (Zeithaml and Bitner, 2003), functional quality is usually the primary determinant of patients' perceptions of quality (Donabedian, 1980). There is growing evidence to suggest that this perceived quality is the single most important variable influencing consumers' perceptions of value, and that this, in turn, affects their intention to purchase products or services (Bolton and Drew.,p1988; Zeithaml et al., 1996).

\section{Studies on perceived service quality in the hospital sector}

Studies to assess perceived service quality have been undertaken in hospital sector in different countries. Donabedian (1980) provided criteria for what constitutes "good care," using the framework of structure (related to physical environment and facilities), process (related to interaction with serviceprovider) and outcome (the result of the interaction). Donabedian developed seven attributes of healthcare quality: efficacy, effectiveness, efficiency, optimality, acceptability, legitimacy, and equity. Jun et al. (1988) identified 11 dimensions of healthcare quality. Eight of these dimensions are part of the well-known Parasuraman model (Parasuraman et al., 1985). Additional three are caring (personal and human involvement), patient outcomes (relief from pain, saving of life, or anger/disappointment with life after medical intervention) and collaboration. Carman (1990) through a study of acute care hospitals identified admission, tangibles accommodation, tangible food, tangible privacy, nursing, explanation visitor access, courtesy, discharge planning, and patient accounting as dimensions explaining perceived service quality for hospitals. 


\section{Research Design}

Proposed Research Model: This study is approached with the use of the proposed model (see Fig. 1).

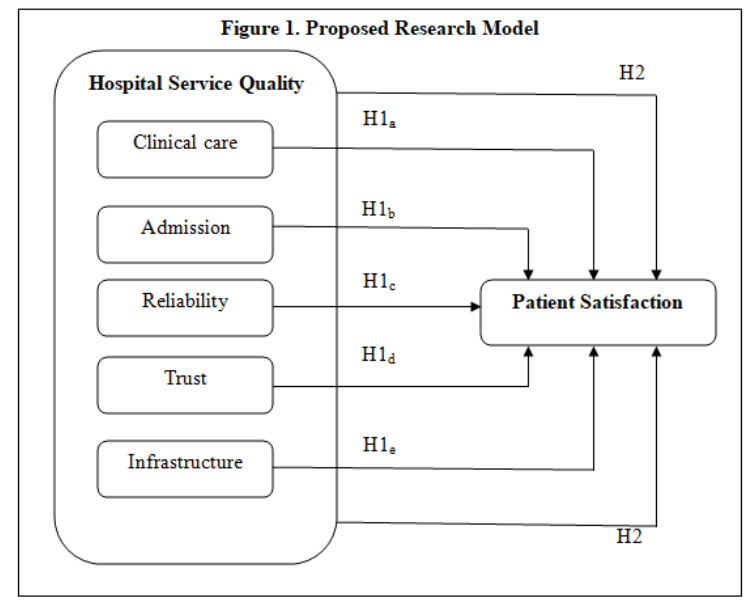

Fig. 1: Proposed research model

\section{Objectives of the Study}

Based on the proposed research model, the objectives of the study are:

1. To study the relationship between various hospitals' service quality dimensions (Clinical care, Admission procedure, Reliability, Trust, and Infrastructure) and patients' satisfaction.

2. To measure the impact of overall perceived service quality on the patients' satisfaction.

\section{Materials and Method}

Both primary research and secondary research (literature review) are followed for this study to achieve these objectives. The scope of the study is limited only to small private hospitals situated in Bellary city, Karnataka, India and 03 hospitals were chosen for the investigation. The survey comprised of three sections. The first section of the questionnaire survey covered the demographic profile of the patients. The second section covered variables relating to the hospital service quality and the third section of the survey consisted of variables relating to patient satisfaction. The attributes are of five point Likert Scale type (1=Strongly Disagree. 5= Strongly Agree).

This study was conducted from January - April 2018. Random sampling technique was used for gathering data from the respondents who were taking medical treatment from the selected hospitals. The purpose behind the study was clearly explained to the patients before gathering information.

\section{Proposed Hypotheses}

The following hypotheses were formulated for this study.

Hypothesis 1: There is a significant impact by the dimensions of perceived service quality (HOSPITAL) on patients' satisfaction
$H_{1}$ : The perceived clinical care dimension of service quality has significant impact on patients' satisfaction. $\boldsymbol{H 1}_{b}$ : The perceived admission procedure dimension of service quality has significant impact on patients' satisfaction.

H1 : The perceived reliability dimension of service quality has significant impact on patients' satisfaction.

$\boldsymbol{H} \boldsymbol{1}_{d}$ : The perceived trust dimension of service quality has significant impact on patients' satisfaction.

$\boldsymbol{H 1}_{e}$ : The perceived infrastructure dimension of service quality has significant impact on patients' satisfaction.

Hypothesis 2: There is a significant impact by the overall perceived service quality on customer (Hospital) on patients' satisfaction.

\section{Reliability of the Instrument}

Data reliability checks were performed using Cronbach's Alpha Test, which is used to establish internal consistency. For this test, the attributes under service quality assessment and satisfaction were considered. If the Cronbach's Alpha value is more than 0.60 , it is considered as the reliability is good.

Table 1: Cronbach's Alpha Test Results: All the Attributes

\begin{tabular}{|c|c|}
\hline Cronbach's Alpha & $\begin{array}{c}\text { N of Items (variables } \\
\text { selected) }\end{array}$ \\
\hline .816 & 28 \\
\hline
\end{tabular}

The Cronbach's alpha value is high at 0.816 , hence it is concluded that the internal consistency and reliability of data are very good. 


\section{Data Analysis and Results}

\section{Demographics Profile of Patients}

A total of 266 patients were approached where 250 completed the questio nnaire showing a response rate of $93 \%$. Amongst these 266 responses 16 were considered invalid because of missing data or unengaged responses. The remaining 250 responses are used for further data analysis, of these 250 respondents $63 \%$ were male, whereas $37 \%$ female. About $21 \%$ were below 25 years of age, $32 \%$ were between 26 and 40 years, $38 \%$ were between the ages of 41 and 55and 9\% were older tha n 55 years. The important levels of educational qualification among the patients were post-graduation and professionals which constituted $45 \%$ and $32 \%$ of the total respondents, respectively. Around $48 \%$ of the respondents earn between Rs.25,001 and Rs.45,000 as monthly income.

\section{Descriptive Analysis on Attributes}

Across the attributes, except a few, considerable portion of respondents have rated 'Agree' or 'Strongly Agree', as the averages are just round 4 here with a stand ard deviation within 1 . The skewness values are within -1 to +1 , with less than 0.5 in many cases, explain that the data variables follow the normality assumption approximately. For further analysis and hypothesis testing, five new variables are defined as below. These are the service quality dimension variables, namely clinical care, Admission procedure, Reliability, Trust, and Infrastructure and for each dimension average value of ratings are given for the attributes. Under, satisfaction, the overall level satisfaction attributes experienced has been considered for the analysis.

Table 2: Descriptive Analysis Results: Dimensions

\begin{tabular}{|l|c|c|}
\hline \multicolumn{1}{|c|}{ Dimensions } & Mean & $\begin{array}{c}\text { Std. } \\
\text { Deviation }\end{array}$ \\
\hline Clinical care & 4.16 & 0.08 \\
\hline Admission procedure & 4.14 & 0.11 \\
\hline Reliability & 4.10 & 0.09 \\
\hline Trust & 4.20 & 0.10 \\
\hline Infrastructure & 4.09 & 0.02 \\
\hline Overall Satisfaction & 4.29 & 0.06 \\
\hline
\end{tabular}

\section{Objective 1 \& Hypothesis Testing 1}

Objective 1: To study the relationship between service quality (Hospital) dimensions (Clinical care, Admission procedure, Reliability, Trust, and Infrastructure) and patients' satisfaction.

\section{Correlation Analysis Results}

The following results indicate that the five dimensions are significantly (at alpha $=0.01,99 \%$ CI) and positively related with Overall satisfaction with service experienced.

Table 3: Correlation Analysis: Dimensions vs. Overall Satisfaction

\begin{tabular}{|l|l|c|}
\hline \multirow{2}{*}{ Dimensions } & $\begin{array}{c}\text { Overall, I was } \\
\text { Satisfied with the } \\
\text { service I experienced }\end{array}$ \\
\hline Clinical care & Pearson Correlation & 0.592 \\
\cline { 2 - 3 } & Sig. (2-tailed) & 0.001 \\
\hline \multirow{2}{*}{$\begin{array}{l}\text { Admission } \\
\text { procedure }\end{array}$} & Pearson Correlation & 0.726 \\
\cline { 2 - 3 } Reliability & Sig. (2-tailed) & 0.001 \\
\cline { 2 - 3 } & Pearson Correlation & 0.696 \\
\cline { 2 - 3 } Trust & Sig. (2-tailed) & 0.001 \\
\cline { 2 - 3 } & Pearson Correlation & 0.797 \\
\cline { 2 - 3 } Infrastructure & Sig. (2-tailed) & 0.001 \\
\cline { 2 - 3 } & Pearson Correlation & 0.647 \\
\cline { 2 - 3 } & Sig. (2-tailed) & 0.001 \\
\hline
\end{tabular}

'Trust' has the large impact (correlation coefficient $=0.797$ ) on the overall satisfaction level, 'Admission procedure' has the second largest impact (correlation coefficient=0.726) followed by 'Reliability', 'Infrastructure' and 'Clinical care' with a correlation coefficient $0.696,0.647$ and 0.592 respectively.
A multiple correlation analysis (table 4.3) results show that there exists a moderate, positive and significant relationship among the five service quality dimensions. It is observed that 'trust' has correlations i.e. 0.65 with Clinical care and 0.88 with Admission procedure. Other cases, it is a substantial level of correlation seen. 
Table 4 Correlation Analysis: Within Service Quality Dimensions

\begin{tabular}{|l|l|c|c|c|c|c|}
\hline \multicolumn{2}{|c|}{ Dimensions } & $\begin{array}{c}\text { Clinical } \\
\text { care }\end{array}$ & $\begin{array}{c}\text { Admission } \\
\text { procedure }\end{array}$ & Reliability & Trust & Infrastructure \\
\hline \multirow{2}{*}{ Clinical care } & Pearson Correlation & 1 & 0.381 & 0.514 & 0.649 & 0.613 \\
\cline { 2 - 7 } & Sig. (2-tailed) & & 0.0001 & 0.0001 & 0.0001 & 0.0001 \\
\hline \multirow{2}{*}{$\begin{array}{l}\text { Admission } \\
\text { procedure }\end{array}$} & Pearson Correlation & & 1 & 0.892 & 0.880 & 0.717 \\
\hline \multirow{2}{*}{ Reliability } & Sig. (2-tailed) & & 0.0001 & 0.0001 & 0.0001 & 0.0001 \\
\hline & Pearson Correlation & & & 1 & 0.885 & .787 \\
\hline \multirow{2}{*}{ Trust } & Sig. (2-tailed) & & & & 0.0001 & 0.0001 \\
\hline \multirow{2}{*}{ Infrastructure } & Pearson Correlation & & & & 1 & 0.808 \\
\cline { 2 - 7 } & Sig. (2-tailed) & & & & & 0.0001 \\
\hline & Pearson Correlation & & & & & 1 \\
\hline & Sig. (2-tailed) & & & & & - \\
\hline
\end{tabular}

It is concluded that there exists a considerable level of relationship among the five service quality dimensions and overall satisfaction level.

\section{Hypothesis 1: Multiple Regression Analysis Results (Individual dimensions)}

The correlation showed that the five dimensions have significant and positive impact on the overall satisfaction level. This is further examined using a linear regression analysis, to understand the extent of impact of each dimension.

Hypothesis.1: There is a significant impact by the dimensions of perceived service quality (Hospital) on patients' satisfaction.

$\mathrm{H} 1_{\mathrm{a}}$ : The perceived Clinical care dimension of service quality has significant impact on patients' satisfaction.

$\mathrm{H} 1_{\mathrm{b}}$ : The perceived Admission procedure dimension of service quality has significant impact on patients' satisfaction.
$\mathrm{H} 1_{c}$ : The perceived Reliability dimension of service quality has significant impact on patients' satisfaction. $\mathrm{H} 1_{\mathrm{d}}$ : The perceived Trust dimension of service quality has significant impact on patients' satisfaction.

$\mathrm{H} 1_{\mathrm{e}}$ : The perceived Infrastructure dimension of service quality has significant impact on patients' satisfaction.

All these hypotheses are tested with alpha $=0.05$ and confidence interval $=95 \%$. The data set satisfies the assumption on sample requirement for regression $(\mathrm{N}=250)$ and normality of variables under consideration.

H1a: The perceived Clinical care dimension of service quality has significant impact on customers' satisfaction.

Table 5 Model Summary: Tangibles

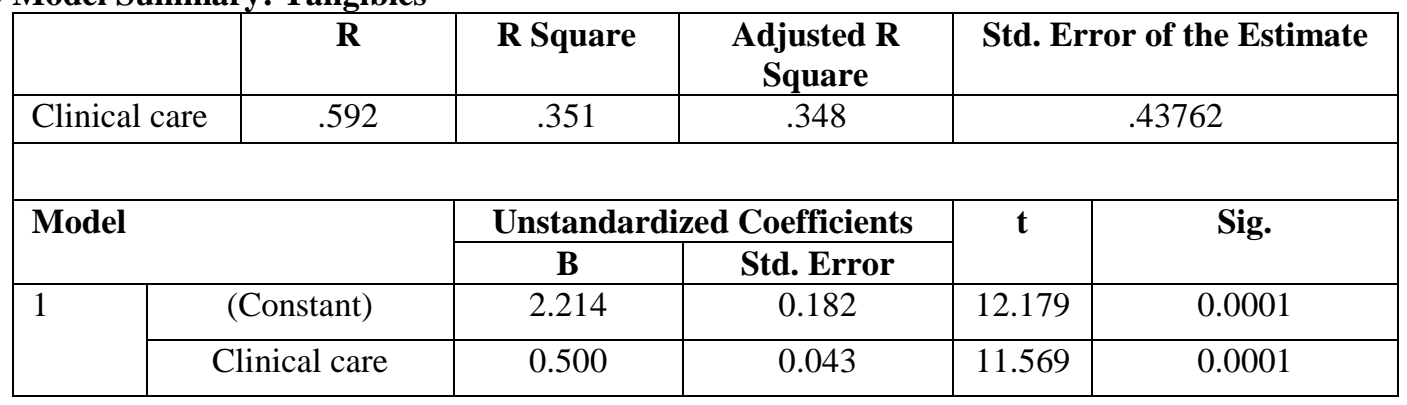

$\mathrm{R}$-Square is the proportion of variance in the dependent variable (Overall Satisfaction) which can be predicted from the independent variable (Clinical care). $\mathrm{R}$-Square $=0.351$ indicates that $35.12 \%$ of the variance in 'Overall Satisfaction' can be predicted by 'Clinical care' variable. In ANOVA, the $\mathrm{p}$ value= $0.0001(<0.05)$ indicates that 'Clinical care' variable really contributes to the overall satisfaction. The Beta coefficient for 'Clinical care' indicates that for every additional unit increase in 'Clinical care' will result in increase in overall satisfaction with 0.500 . It is also significant as the significant value is 0.0001 , which is less than 0.05 . Also, the $t$-value is comparatively high at 11.569, which implies that 'Clinical care' contributes significantly to the overall satisfaction.

Conclusion: The perceived Clinical care dimension of service quality has significant impact on customers' satisfaction.

H1 $_{b}$ : The perceived Admission procedure dimension of service quality has significant impact on customers' satisfaction. 
Table 6: Model Summary: Admission procedure

\begin{tabular}{|l|c|c|c|c|}
\hline & $\mathbf{R}$ & $\begin{array}{c}\mathbf{R} \\
\text { Square }\end{array}$ & $\begin{array}{c}\text { Adjusted } \\
\text { R Square }\end{array}$ & $\begin{array}{c}\text { Std. Error of } \\
\text { the Estimate }\end{array}$ \\
\hline $\begin{array}{l}\text { Admission } \\
\text { procedure }\end{array}$ & 0.726 & 0.528 & 0.526 & 0.373 \\
\hline
\end{tabular}

\begin{tabular}{|c|l|l|l|l|c|}
\hline \multicolumn{2}{|c|}{ Model } & \multicolumn{2}{|c|}{$\begin{array}{c}\text { Unstandardized } \\
\text { Coefficients }\end{array}$} & \multirow{2}{*}{ Sig. } & \\
\cline { 2 - 4 } & B & Std. Error & & \\
\hline \multirow{2}{*}{1} & (Constant) & 1.837 & 0.149 & 12.2921 & 0.0001 \\
\cline { 2 - 6 } & $\begin{array}{l}\text { Admission } \\
\text { procedure }\end{array}$ & 0.593 & 0.036 & 16.645 & 0.0001 \\
\hline
\end{tabular}

R-Square $=0.528$ indicates that $52.8 \%$ of the variance in 'Overall Satisfaction' can be predicted by 'Admission procedure' variable. In ANOVA, the $\mathrm{p}$ value $=0.0001 \quad(<0.05)$ indicates that 'Admission procedure' variable really contributes to the overall satisfaction. The Beta coefficient for 'Admission procedure' indicates that for every additional unit increase in 'Admission procedure' will result in increase in overall satisfaction with 0.593 . It is also significant at $5 \%$ alpha level. Also, the t-value is comparatively high at 16.64 , which implies that
'Admission procedure' contributes significantly to the overall satisfaction.

Conclusion: The perceived Admission procedure dimension of service quality has significant impact on customers' satisfaction.

H1c: The perceived Reliability dimension of service quality has significant impact on customers' satisfaction.

Table 7: Model Summary: Reliability

\begin{tabular}{|l|c|c|c|c|}
\hline & R & R Square & $\begin{array}{c}\text { Adjusted } \\
\text { R Square }\end{array}$ & $\begin{array}{c}\text { Std. Error of } \\
\text { the Estimate }\end{array}$ \\
\hline Reliability & 0.696 & 0.485 & 0.483 & 0.389 \\
\hline
\end{tabular}

\begin{tabular}{|l|c|c|c|c|c|}
\hline \multirow{2}{*}{ Model } & \multicolumn{2}{|c|}{$\begin{array}{c}\text { Unstandardized } \\
\text { Coefficients }\end{array}$} & \multirow{2}{*}{ Sig. } & \\
\cline { 3 - 5 } \multicolumn{2}{|c|}{} & B & Std. Error & & \\
\hline \multirow{2}{*}{1} & (Constant) & 1.889 & .159 & 11.858 & 0.0001 \\
\cline { 2 - 6 } & Reliability & 0.586 & .038 & 15.274 & 0.0001 \\
\hline
\end{tabular}

R-Square $=0.485$ indicates that $48.5 \%$ of the variance in 'Overall Satisfaction' can be predicted by 'Reliability' variable. In ANOVA, the $p$ value $=0.0001$ $(<0.05)$ indicates that 'Reliability' variable really contributes to the overall satisfaction. The Beta coefficient for 'Reliability' indicates that for every additional unit increase in 'Reliability' will result in increase overall satisfaction with 0.586 . It is also significant at5\% alpha level. Also, the t-value is comparatively high at 15.274, which implies that 'Reliability 'contributes significantly to the overall satisfaction.

Conclusion: The perceived Reliability dimension of service quality has significant impact on patients' satisfaction.

$\mathrm{H} 1_{\mathrm{d}}$ : The perceived Trust dimension of service quality has significant impact on customers' satisfaction.

Table 8: Model Summary: Trust

\begin{tabular}{|c|c|c|c|c|c|c|}
\hline 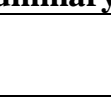 & $\mathbf{R}$ & R Square & Adjusted R Squ & & & $\begin{array}{l}\text { rror of } \\
\text { timate }\end{array}$ \\
\hline Trust & 0.797 & 0.636 & 0.634 & & & 327 \\
\hline \multirow{2}{*}{\multicolumn{2}{|c|}{ Model }} & \multicolumn{2}{|c|}{ Unstandardized Coefficients } & \multirow{2}{*}{\multicolumn{2}{|c|}{$\mathbf{t}$}} & \multirow[t]{2}{*}{ Sig. } \\
\hline & & B & Std. Error & & & \\
\hline \multirow[t]{2}{*}{1} & nstant) & 1.273 & 0.147 & & 683 & 0.0001 \\
\hline & Trust & 0.719 & 0.035 & & 811 & 0.0001 \\
\hline
\end{tabular}


R-Square $=0.636$ indicates that around $63.6 \%$ of the variance in 'Overall Satisfaction' can be predicted by 'Trust variable. The Beta coefficient for 'Trust' indicates that for every additional unit increase in 'Trust' will result in increase in overall satisfaction with 0.719.It is also significant at alpha $=0.05$. The $\mathrm{t}$-value is comparatively higher (20.811).
This indicates that 'Trust' contributes significantly $\mathrm{t}$ o the overall satisfaction.

Conclusion: The perceived Trust dimension of service quality has significant impact on patients' satisfaction.

$\mathrm{H} 1_{\mathrm{e}}$ : The perceived Infrastructure dimension of service quality has significant impact on patients' satisfaction.

Table 9: Model Summary: Infrastructure

\begin{tabular}{|l|c|c|c|c|}
\hline & R & R Square & $\begin{array}{c}\text { Adjusted } \\
\text { R Square }\end{array}$ & $\begin{array}{c}\text { Std. Error of } \\
\text { the Estimate }\end{array}$ \\
\hline Infrastructure & 0.647 & 0.419 & 0.416 & 0.414 \\
\hline
\end{tabular}

\begin{tabular}{|l|l|c|c|c|c|}
\hline \multicolumn{2}{|c|}{ Model } & \multicolumn{2}{|c|}{$\begin{array}{c}\text { Unstandardized } \\
\text { Coefficients }\end{array}$} & \multirow{2}{*}{ Sig. } & \\
\cline { 3 - 4 } \multicolumn{2}{|c|}{} & B & Std. Error & & \\
\hline \multirow{2}{*}{1} & (Constant) & 1.708 & 0.195 & 8.751 & 0.0001 \\
\cline { 2 - 5 } & Infrastructure & 0.631 & 0.047 & 13.360 & 0.0001 \\
\hline
\end{tabular}

R-Square $=0.419$ indicates that only around $41.9 \%$ of the variance in 'Overall Satisfaction' can be predicted by 'Infrastructure' variable. In ANOVA, the $p$ value $=\quad 0.0001 \quad(<0.05)$ indicates that 'Infrastructure' variable really contribu tes to theoverall satisfaction. The Beta coefficient for 'Infrastructure' indicates that for every additional unit increase in 'Infrastructure' will result in increase in overall satisfaction with 0.631 . It is also significant at alpha $=0.05$. The $t$-value is comparatively high at
13.360. This indicates that 'Infrastructure' contributes significantly to the overall satisfaction.

Conclusion: The perceived Infrastructure dimension of service quality has significant impact on patients' satisfaction.

\section{Hypothesis 1: Multiple Regression Analysis Results (All 5 dimensions)}

It is further examined by considering all the five dimensions together and analyzing their contribution towards overall satisfaction level.

Table 10: Model Summary: All 5 Service Quality Dimensions

\begin{tabular}{|l|c|c|c|c|}
\hline Dimensions & R & R Square & $\begin{array}{c}\text { Adjusted } \\
\text { R Square }\end{array}$ & $\begin{array}{c}\text { Std. Error of } \\
\text { the Estimate }\end{array}$ \\
\hline $\begin{array}{l}\text { Clinical care, Admission } \\
\text { procedure, Reliability, } \\
\text { Trust, Infrastructure }\end{array}$ & 0.816 & 0.666 & 0.660 & 0.316 \\
\hline
\end{tabular}

\begin{tabular}{|c|c|c|c|c|c|}
\hline \multirow{2}{*}{\multicolumn{2}{|c|}{ Model }} & \multicolumn{2}{|c|}{$\begin{array}{l}\text { Unstandardized } \\
\text { Coefficients }\end{array}$} & \multirow[b]{2}{*}{$\mathbf{t}$} & \multirow[b]{2}{*}{ Sig. } \\
\hline & & B & Std. Error & & \\
\hline \multirow[t]{6}{*}{1} & (Constant) & 1.032 & 0.162 & 6.390 & 0.000 \\
\hline & Clinical care & .210 & .050 & 4.215 & 0.000 \\
\hline & Admission procedure & .336 & .086 & 3.899 & 0.000 \\
\hline & Reliability & -.154 & .082 & -1.886 & 0.061 \\
\hline & Trust & .411 & .106 & 3.881 & 0.000 \\
\hline & Infrastructure & -.025 & .066 & -.388 & 0.698 \\
\hline
\end{tabular}

$\mathrm{R}$-Square is the proportion of variance in the dependent variable (Overall patient Satisfaction) which can be predicted from the independent variables (five dimensions). R-Square $=0.666 \quad$ means that $66.6 \%$ of the variance in 'Overall Patient Satisfaction' can be predicted by these five dimensions. In ANOVA, the $\mathrm{p}$ value $=0.0001(<0.05)$ indicates that all the five dimensions really contribute to the overall satisfaction. It is observed that all the dimension except 'Reliability' and 'Infrastructure' have significant (sig value < 0.05) impact on the overall satisfaction. 'Clinical care', 'Admission procedure' and 'Trust' are the key drivers of overall patient satisfaction level, with beta coefficients $0.210,0.336$ and 0.411 respectively. These three have positive higher t-values ( 4.215, 3.899 and 3.881) The dimension 'Reliability' also has major 
contribution towards overall satisfaction, in a negative way, means any reliability attributes will pull down the overall satisfaction level, if not performed well. 'Infrastructure' dimension has a very low and insignificant impact on the overall satisfaction. The hospitals' need to improve aspect under Reliability to ensure higher satisfaction levels in the future.

Conclusion: It is concluded that the dimensions Trust, Admission procedure and Clinical care are the major contributors towards the overall patient satisfaction level.

\section{Overall Conclusion: Objective 1 and Hypothesis 1}

Using correlation and regression analyses, it is concluded that 'Clinical care' has large impact on the overall patient satisfaction level, 'Admission procedure
' and ' Trust' both has the second largest impact (correlation). Reliability and Infrastructure have low impact on the overall satisfaction level. It is also further concluded that that 'Trust', 'Admission procedure' and 'Clinical care' are the major contributors towards the overall satisfaction level.

Objective 2 and Hypothesis 2

Objective 2: To measure the impact of overall perceived service quality on the patients' satisfaction.

Hypothesis 2: There is a significant impact by the overall perceived service quality (Hospital) on patients' satisfaction

'Overall perceived service quality' is arrived by averaging all the individual attributes of those five dimensions. A multiple correlation analysis is used to study the impact of overall perceived service quality on the patients' satisfaction.

\begin{tabular}{|l|l|c|}
\hline \multicolumn{2}{|c|}{ Overall Service Quality } & $\begin{array}{c}\text { Overall, I was satisfied with } \\
\text { the service I experienced }\end{array}$ \\
\hline $\begin{array}{l}\text { Overall Service } \\
\text { Quality }\end{array}$ & Pearson Correlation & 0.781 \\
\cline { 2 - 3 } & Sig. (2-tailed) & 0.0001 \\
\hline
\end{tabular}

The correlation analysis indicates that there exists a strong, positive and significant relationship exists between overall service quality and overall satisfacti on level. Any unit of change in overall service quality will impact $78 \% \mathrm{i}$ $\mathrm{n}$ overall satisfaction level.

\section{Discussion}

It is a well-known fact the patient satisfaction leads to repeated visits and recommendation of service to others. This research concludes that the five dimensions of service quality have significant positive impact on the overall satisfaction of the patients. It implies that the hospitals contacted in this study provide better service, treatment, etc., to attract the patients and maintain their status quo. There are certain elements like 'Reliability' and 'Infrastructure' in which the hospitals need to understand the gaps and improve them as well to win over the competition in the healthcare industry in Bellary.

\section{Managerial Implications}

The study findings have significant implications for hospital administrators. The study findings would help managers to ascertain priorities of patients. This study can also be used as a tool by the hospital administrators to identify various dimensions of hospital service quality where improvements are needed to enhance the patients' satisfaction levels. Since the hospital sector has become intensively competitive on account of globalization, therefore, hospital administrators need to understand how patients rate service quality and what critical dimensions contribute to improving service quality. On the other hand, from a practical perspective, the hospital administrator could use the findings of the present study to improve the service quality of a hospital, which will ensure its survival in a highly competitive market.

\section{Limitations of the Study and Scope for Future Research}

The most important limitation of this study is the utilization of random sampling. Therefore the outcomes may not be illustrative of the patients' perception of the entire population of the study area. Future investigations in hospital service quality could address this issue by utilizing some other methods of sampling like for example, purposive sampling as it's easier to make generalizations about the sample. Second, several other factors can be incorporated as results of hospital service quality. For instance, patient's loyalty, behavioural intentions and so forth, this investigation considered patient perception towards hospital service quality and future examinations ought to look at attenders' perceptions towards hospital service quality and its consequences on hospital performance.

\section{References}

1. Baltussen, R.M.P.M., Ye, Y., Haddad, S. and Sauerborn, R.S. (2002), "Perceived quality of care of primary health care services in Burkino Paso", Health Policy and Planning, Vol. 17 No. 1, pp. 42

2. Bigne, E., Moliner, M.A. and Sanchez, J. (2003), "Perceived quality and satisfaction in multiservice organizations: the case of Spanish public services", Journal of services Marketing, Vol. 17 No. 4, pp. 420-42.

3. Bolton, R.N. and Drew, J.H. (1988), "A model of perceived service value", in Frazier, G., Ingene, C., Aaker, D., Ghosh, A., Kinnear, T., Levy, S., Staelin, R. and Summers, J. (Eds), Efficiency and Effectiveness in Marketing: AMA Educator's Proceedings, American 
Marketing Association Series, No. 54, American

Marketing Association, Chicago, IL, p. 213.

4. Carman, J.M. (1990), "Consumer perceptions of service quality: an assessment of the SERVQUAL dimensions", Journal of Retailing, Vol. 66 No. 1, pp. 33-5.

5. Gronroos, C. (1984), "A service quality model and its marketing implications", European Journal of Marketing, Vol. 18 No. 4, pp. 36-44.

6. Dabholkar, P.A., Thorpe, D.I. and Rentz, J.O. (1996), “A measure of service quality for retail stores: scale development and validation", Journal of the Academy of Marketing Science, Vol. 24 No. 1, pp. 3-16.

7. Donabedian, A. (1980), "The definition of quality and approaches to its assessment", in Donabedian, A. (Ed.), Explorations in Quality Assessment and Monitoring, Vol. 1, Health Administration Press, Ann Arbor, MI.

8. Ingram, H. and Daskalakis, G. (1999), "Measuring quality gaps in hotels: the case of Crete", International Journal of Contemporary Hospitality Management, Vol. 11 No. 1, pp. 24-30.

9. Jun, M., Peterson, R.T. and Zsidisin, G.A. (1988), “The identification and measurement of quality dimensions in healthcare: focus group interview results", Healthcare Management Review, Vol. 23 No. 4, p. 81.

10. Lynch, J. and Schuler, D. (1990) 'Consumer evaluation of the quality of hospital services from an economics of information perspective', Journal of Health Care Marketing, Vol. 10 No. 2, pp. 16-22.

11. Massachusetts Health Quality Partnership (1988), Results of Hospital Patient Care Survey, Massachusetts Health Quality Partnership, Boston, MA.

12. Parasuraman, A., Zeithaml, V.A. and Berry, L.L. (1988), "SERVQUAL: a multiple item scale for measuring consumer perception of service quality", Journal of Retailing, Vol. 64 No. 1, pp. 12-37.

13. Rust, R.T. and Oliver, R.L. (1994), "Service quality: insights and implications from the frontier service quality", in Rust, R.T. and Oliver, R.L. (Eds), New Directions in Theory and Practice, Sage, Thousand Oaks, CA.

14. Zeithaml, V.A. and Bitner, M.J. (2003), Services Marketing: Integrating Customer Focus across the Firm, 3rd ed., McGraw-Hill, New York, NY.

15. Zeithaml, V.A., Berry, L.L. and Parasuraman, A. (1996), "The behavioral consequences of service quality", Journal of Marketing, Vol. 60, pp. 31-46.

16. Zeithaml, A., Leonard L.B. and Parasuraman, A. (1988) 'Communication and Control Processes in the Delivery of Service Quality', Journal of Marketing, Vol. 52, pp. 3548. 